\title{
Differential conditioning along two dimensions and stimulus generalization of the rabbit's nictitating membrane response*
}

\author{
JOHN W. MOORE and FREDERICK W. MIS \\ University of Massachusetts, Amherst, Mass. 01002
}

Rabbits received classical differential conditioning of the nictitating membrane response to tones differing in both frequency and intensity. Subsequent tests of stimulus generalization along the frequency dimension (at the intensity of $\mathrm{CS}+$ ) indicated significant suppression of responding to the CS- frequency compared with control groups conditioned to CS+ alone. These results are consistent with Hullian (gradient interaction) theories of discrimination learning.

The operant conditioning literature contains numerous demonstrations that intradimensional discrimination training produces, among other effects, a steeper generalization gradient (most notably on the Sside of the peak) than that obtained as a result of single-stimulus training to S+. Liu (1971) has reported similar results for the classically conditioned nictitating membrane (NM) response of the rabbit. In Liu's experiment, differential conditioning to tones of $1200 \mathrm{~Hz}$ (CS+), $2400 \mathrm{~Hz}$ (CS-), and equal intensity ( $75 \mathrm{~dB}$ SPL) resulted in a sharper relative generalization gradient along the frequency dimension than that obtained from a single-stimulus control group conditioned to the $1200-\mathrm{Hz}$ tone. The greatest suppression of generalized responding occurred on the CS - side of the gradient, thereby conforming with the operant literature and with traditional Hullian theories of discrimination learning. However, Liu (1971) found that when CS+ and CS- differed in both frequency and intensity (CS+ was a $1200-\mathrm{Hz}$ tone of $75 \mathrm{~dB}$ and CSwas a tone of $2400 \mathrm{~Hz}$ of $60 \mathrm{~dB}$ ), the observed generalization gradient along the frequency dimension was indistinguishable from that of the single-stimulus control.

Two factors may have contributed to Liu's failure to observe any effect of differential conditioning on generalization in the two-dimensional case: (1) Conditioned inhibition from the less intense CSmay have been too weak to influence excitatory generalization; (2) the psychophysical distance between $\mathrm{CS}+$ and $\mathrm{CS}-$ in the frequency by intensity space may have been so great that any inhibition at CS-could not generalize far enough to influence the excitatory gradient. The present investigation sought additional

*This research was supported by National Science Foundation Grant GB 24557. Requests for reprints should be sent to John W. Moore, Department of Psychology, Middlesex House, University of Massachusetts, Amherst, Massachusetts 01002. information on the excitatory auditory frequency generalization as a function of differential conditioning to tones differing in both frequency and intensity.

\section{METHOD \\ Subjects and Apparatus}

Sixty-four New Zealand rabbits were run, four at a time, in individual soundproofed and ventilated file drawers while restrained in Plexiglas boxes like those described by Gormezano (1966). A potentiometer mounted on the S's head was connected by a small metal hook and thread to a nylon loop sutured into the nictitating membrane (NM) of the right eye. Movement of the NM resulted in a dc signal which was amplified and recorded on a Grass 5D oscillograph. A CR was defined as a pen deflection of $1 \mathrm{~mm}$ (corresponding to an extension of the NM of less than $1 \mathrm{~mm}$ ) or greater within the $400-\mathrm{msec}$ interstimulus interval. The CSs were $450-\mathrm{msec}$ pure tones of 75 or $95 \mathrm{~dB}$ SPL, terminating together with the 50 -msec UCS. The UCS was a 2-mA ac shock, delivered through wound clip electrodes (Clay-Adams, $9 \mathrm{~mm}$ ) attached to the infraorbital region of the right eye. A low level (76 dB SPL) of continuous masking noise was provided by a speaker located directly in front of $S$.

\section{Design and Procedure}

Ss were divided into eight groups of eight animals each, according to a 2 by 2 by 2 factorial design: (a) One factor of the design was single-stimulus (simple) conditioning to one CS vs differential conditioning to two CSs; (b) another factor, orthogonal to (a), was the intensity of the reinforced CS (95 vs $75 \mathrm{~dB}$ ). For the differential conditioned groups, CS - was $95 \mathrm{~dB}$ when CS+ was $75 \mathrm{~dB}$ and $75 \mathrm{~dB}$ when CS+ was $95 \mathrm{~dB}$. (c) The third orthogonal factor was the frequency of the reinforced CS $(900 \mathrm{vs} 1500 \mathrm{~Hz})$. For the differential conditioning groups, CSwas $900 \mathrm{~Hz}$ when CS+ was $1500 \mathrm{~Hz}$ and $1500 \mathrm{~Hz}$ when CS+ was $900 \mathrm{~Hz}$. The day following suturing and adaptation to restraint, differential conditioning Ss received four successive daily sessions of $50 \mathrm{CS}+$ and $50 \mathrm{CS}$ - trials (in an unsystematic order) at a constant ITI of $30 \mathrm{sec}$. Single-stimulus Ss received four daily sessions of 50 reinforced trials, at an ITI of $60 \mathrm{sec}$. Training was followed by two daily extinction-generalization test sessions, consisting of 15 presentations each of seven test tones $(300,600$, $900,1200,1500,1800$, and $2100 \mathrm{~Hz}$ ) at the intensity of CS+.

\section{RESULTS AND DISCUSSION}

\section{Acquisition}

Figure 1 depicts the percentage of CRs for simple (single-stimulus) and differential conditioning groups as a function of day of training. Analysis of variance of $\mathrm{CR}$ frequency to the reinforced CS, pooled over the 4 days of acquisition, indicated significantly more CRs to the 95- $\mathrm{dB}$ tone than to the $75-\mathrm{dB}$ tone $[\mathrm{F}(1,56)=17.21$, $\mathrm{p}<.001]$.

An analysis of variance of CR frequency confined to the differential conditioning groups, with CS+ and CSas a within-Ss factor, indicated a significant difference in responding to CSt and $\mathrm{CS}-[\mathrm{F}(1,28)=158.99$, 


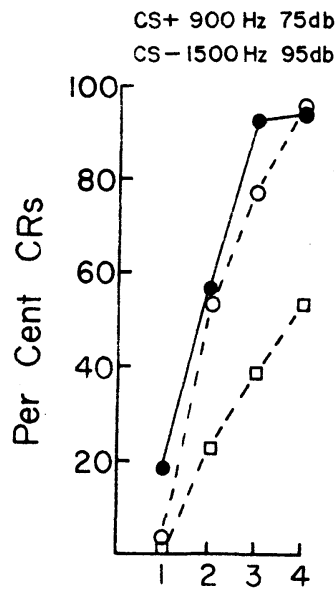

$\mathrm{CS}+90 \mathrm{CHz} 95 \mathrm{db} \quad \mathrm{CS}+1500 \mathrm{~Hz} 75 \mathrm{db}$ $\mathrm{CS}-1500 \mathrm{~Hz} \quad 75 \mathrm{db} \quad \mathrm{CS}-900 \mathrm{~Hz} 95 \mathrm{db}$

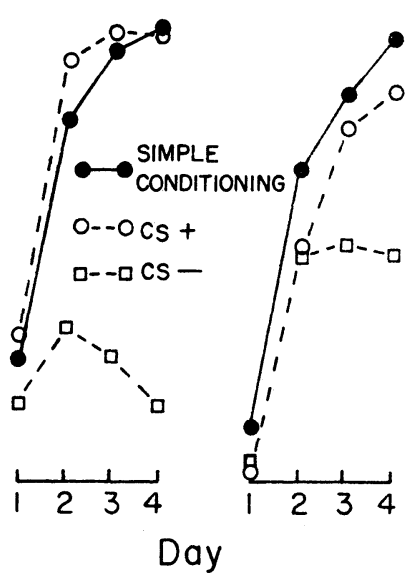

$\mathrm{p}<.001]$. Analysis of variance also indicated that differentiation was greater for groups trained with a CS+ of $95 \mathrm{~dB}$ and $\mathrm{CS}-$ of $75 \mathrm{~dB}$ than vice versa $[F(1,28)=39.33, p<.001]$. This difference was due to both a higher level of responding to $\mathrm{CS}+$ and a considerably lower level of responding to $\mathrm{CS}-$ in the former case compared with the latter. This pattern of results is basically consistent with other rabbit (Schneiderman et al, 1971) and human conditioning studies (e.g., Moore, 1964).

\section{Stimulus Generalization}

The mean relative generalization gradients for each
$\mathrm{CS}+1500 \mathrm{~Hz} 95 \mathrm{db}$

$\mathrm{CS}-900 \mathrm{~Hz} 75 \mathrm{db}$

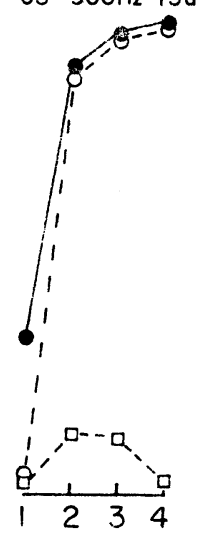

Fig. 1. Percentage of $\mathrm{CRs}$ as a function of day of training for Experiment $I$.

group, pooled over the two test sessions, are depicted in Fig. 2. In order to determine whether differential conditioning affected frequency generalization, the relative percentage of CRs to the CS- frequency of differential groups was contrasted with the relative percentage of CRs to the same frequency of simple conditioning controls. Figure 2 shows that this measure was consistently lower, on the average, for differential conditioning groups than for their respective controls, and an analysis of variance indicated a significant main effect of differential vs simple conditioning on relative responding to the $\mathrm{CS}-$ frequency $[\mathrm{F}(1,56)=7.90$, $\mathrm{p}<.01]$.

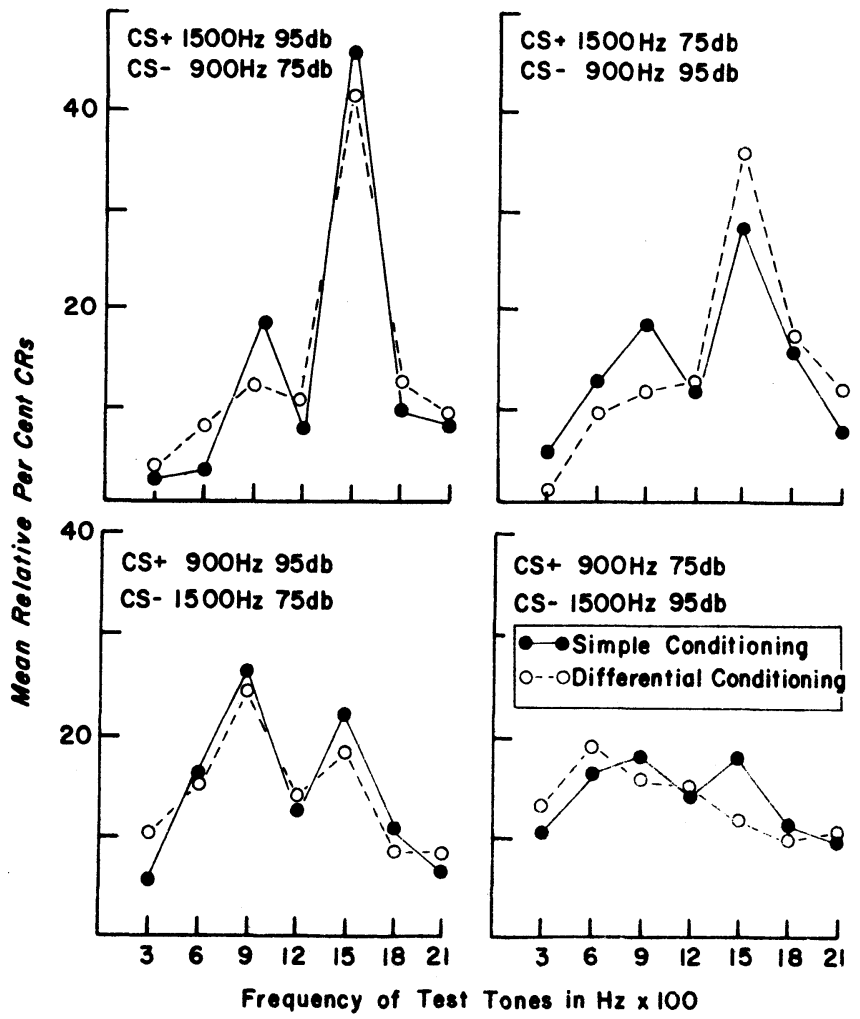

Fig. 2. Mean relative percentage of CRs to test tones, pooled over the two test sessions of Experiment $\mathbf{I}$. 
Figure 2 reveals a depression of generalized responding at the center test frequency $(1200 \mathrm{~Hz})$ in six out of eight gradients. This effect may have been due to generalized extinction inhibition from the other test stimuli. Such generalization effects would tend to be greatest at the center frequency. However, this curious depression at $1200 \mathrm{~Hz}$ was not statistically significant according to a variety of tests.

The principal finding of this experiment is that differential conditioning along two dimensions affected generalization in a manner consistent with traditional Hullian theory of discrimination learning. This theory states that the observed gradient represents the interaction of underlying excitatory and inhibitory gradients. In the present experiment, gradient interaction is reflected in the finding that the generalization gradients of differential conditioning groups were suppressed on the CS- side of the test dimension in comparison with controls. The absence of other effects of differential conditioning on generalization does not necessarily argue against gradient interaction. Dramatic distortions of the observed gradients of the differential conditioning groups, such as peak and area shifts (cf. Moore, 1972), were not anticipated because of the relatively large separation between CS+ and CS - in the two-dimensional frequency by intensity space. Peak shifts along the audio-frequency dimension probably necessitate the use of CSs which are psychophysically closer together.

\section{REFERENCES}

Gormezano, I. Classical conditioning. In J. B. Sidowski (Ed.), Experimental methods and instrumentation in psychology. New York: McGraw-Hill, 1966.

Liu, S. S. Differential conditioning and generalization of the rabbit's nictitating membrane response. Journal of Comparative \& Physiological Psychology, 1971, 77, 136-142.

Moore, J. W. Differential eyelid conditioning as a function of the frequency and intensity of auditory CSs. Journal of Experimental Psychology, 1964, 68, 250-259.

Moore, J. W. Stimulus control: Studies of auditory generalization in rabbits. In A. H. Black and W. F. Prokasy (Eds.), Classical conditioning II: Current theory and research. New York: Appleton-Century-Crofts, 1972.

Schneiderman, N., Pearl, L., Wilson, W., Metcalf, F., Moore, J. W., \& Swadiow, $\dot{H}$. A. Stimulus control in rabbits (Oryctolagus cuniculus) as a function of different intensities of intracranial stimulation. Journal of Comparative \& Physiological Psychology, 1971, 76, 175-186.

(Received for publication November 16, 1972.) 